\title{
Potencial utilidad de la excreción fecal de ARN de SARS-CoV-2
}

Dr. Daniel Ricardo Jiménez Corado ${ }^{1}$ Dra. María Fernanda Aquino Camey ${ }^{2}$

DOI del artículo: 10.36631/Arrupe.2021.06.01

Fecha de recepción: 26/1/2021

Fecha de aceptación: 28/10/2021

\section{Resumen}

El objetivo de este artículo es introducir al lector a la epidemiología basada en el monitoreo de aguas residuales, una herramienta que podría contribuir en el control de la pandemia por coronavirus tipo 2 causante de síndrome respiratorio agudo severo (abreviado SARSCoV-2 por sus siglas en inglés). Se ha reportado la detección de ARN perteneciente a SARS-CoV-2 en algunos fluidos y desechos corporales como saliva, heces, orina y esputo de pacientes con la enfermedad. La excreción del genoma viral en heces de personas con la enfermedad ha creado una oportunidad, para evaluar la utilidad epidemiológica de la detección del genoma viral en aguas residuales. Se ha reportado la detección de ARN perteneciente a SARS-CoV-2, en muestras de plantas de tratamiento de aguas residuales (PTAR) de distintos países. Se han propuesto diversas utilidades, que podrían tener esta herramienta epidemiológica, en la actual pandemia de SARS-CoV-2.

Palabras clave: coronavirus, SARS-CoV-2, epidemiología basada en el monitoreo de aguas residuales

\section{Abstract}

The purpose of this article is to introduce our readers, about wastewater based epidemiology, a tool that could contribute to the control of the actual pandemic due to coronavirus type 2 causant of severe acute respiratory syndrome (abbreviated SARS-CoV-2). Detection of RNA from SARS-CoV-2 has been reported to be found in fluids and bodily wastes, like saliva, feces, urine and sputum, of patients with the disease. Viral genome excretion in feces of persons with the disease, provides an opportunity to evaluate the epidemiologic utility of viral genome detection in waste water. Detection of RNA from SARS-CoV-2 has been reported in samples collected from wastewater treatment plants in many countries. There is a variety of proposed utilities that the use of

1 Médico y cirujano, Magna Cum Laude, por la Universidad Rafael Landívar, octubre de 2019; investigador asociado del Instituto de Investigación y Estudios Superiores en Ciencias de la Salud (lecis).

${ }^{2}$ Médica y cirujana, Cum Laude, por la Universidad Rafael Landívar, octubre 2019; investigadora asociada del Instituto de Investigación y Estudios Superiores en Ciencias de la Salud (lecis). 
wastewater based epidemiology could provide during the actual SARSCoV-2 pandemic.

Key words: coronavirus, SARS-CoV-2, wastewater based epidemiology

\section{Introducción}

SARS-CoV-2 es un virus que se transmite principalmente a través de gotas de 5 a 10 micrómetros de diámetro, las cuales se expulsan mientras una persona tose, estornuda, grita, etc. Se han descrito otras vías de transmisión con menor impacto en la transmisión del virus $(1,2,3,4,5)$. Se ha detectado ARN perteneciente a SARS-CoV-2 y, en algunos casos virus viable, en algunos fluidos y desechos corporales, como saliva, heces, orina y esputo $(2,6)$. Aunque aún no se conoce la capacidad de transmisión oro-fecal de SARS-CoV-2, la presencia de ARN en las heces de personas con la enfermedad ha creado una oportunidad, para evaluar la utilidad de la detección del genoma viral en aguas residuales. La epidemiología basada en el monitoreo de aguas residuales es una herramienta, que históricamente tuvo un gran impacto en la detección y control de brotes de virus, como polio, norovirus y hepatitis $A$ y, en otras instancias, ha sido utilizada con fines de rastreo de drogas ilícitas, opioides principalmente (7).

\section{Epidemiología basada en el monitoreo de aguas residuales: marco conceptual}

Para el funcionamiento de la epidemiología basada en el monitoreo de aguas residuales, el primer paso es determinar el biomarcador que se detectará, en este caso, ARN de SARS-CoV-2. Al excretarse, el biomarcador de interés, por las personas con la enfermedad, ya sea en las heces $u$ orina, este ingresa hacia el sistema de drenaje, el cual desemboca en una planta de tratamiento de aguas residuales. En la planta de tratamiento se toma la muestra y posteriormente se procesa para determinar la presencia/ausencia del biomarcador de interés (8).

La detección de ARN del virus, en las heces de los pacientes con la enfermedad, varía según el estudio que se evalúe, está descrito desde $0 \%$ hasta $100 \%$ de detección. El genoma viral puede ser detectado en las heces de pacientes que se encuentren en diversas fases de la enfermedad, como pacientes presintomáticos, asintomáticos, con cuadros clínicos leves, moderados y graves $(2,3,9,10,11)$. Al considerar la excreción fecal de ARN de SARSCoV-2, se ha demostrado la presencia de dicho genoma viral en plantas de tratamiento de aguas residuales (PTAR) de distintos países, como Holanda, Francia, China, Estados Unidos, Australia, entre otros. La concentración de genoma viral, que puede llegar a niveles de hasta 106 genomas virales por litro de agua residual, cambia y depende de diversas variables, como metodología de muestreo, manejo y concentración de la muestra, temperatura y flujo del agua y múltiples aspectos ambientales (presencia de materia orgánica y sólidos suspendidos, oxidantes y microorganismos antagonistas). Se ha demostrado que la detección del genoma viral en las aguas 
residuales pertenecientes a áreas sin casos, inicia desde días a semanas previo a que se confirme el primer caso en dichas áreas $(2,3,9,10)$.

\section{Utilidades de la epidemiología basada en el monitoreo de aguas residuales para la pandemia de SARS-CoV-2}

Se han descrito diversas utilidades que tiene esta herramienta epidemiológica y, actualmente, se busca implementar para la pandemia actual en diversos países; entre dichas utilidades se encuentran $(2,7,8,12)$ :

1) Estimar la prevalencia de la enfermedad, incluye la cantidad aproximada depacientes asintomáticos, quienes normalmente son difíciles de cuantificar derivado de que no acuden a los servicios de salud. La prevalencia se estimaría con base en la correlación cuantitativa de niveles de ARN con la prevalencia de casos registrados.

2) Determinar las áreas geográficas hacia las cuales el virus se ha diseminado.

3) Monitoreo de la evolución del genoma viral a través del tiempo.

4) Detección de fluctuaciones en el número de casos a través del tiempo.

5) Detección temprana, lo cual permite la búsqueda de casos y sus contactos, con mayor rapidez. Se ha propuesto el uso de esta herramienta, como complementaria al tamizaje individual, pues permite detectar la presencia de ARN en una población o subpoblación, previo a que se manifiesten los primeros casos. Al detectar el genoma viral en cierta área, se podrían dirigir las pruebas diagnósticas hacia quienes forman parte de esa población o subpoblación. Subpoblaciones como aeropuertos, universidades, hospitales, prisiones, entre otras, podrían obtener el mayor beneficio.

6) Crear «mapas de calor», basados en análisis cuantitativos de la cantidad de ARN viral detectada en las aguas residuales pertenecientes a cada una de esas áreas, posibilita identificar las áreas de interés según los análisis cuantitativos.

7) Determinar la introducción o reintroducción del virus a un área geográfica específica, donde previamente no se había detectado virus o la detección fue mitigada. 


\section{Respuestas a incertidumbres en el uso de epidemiología basada en el monitoreo de aguas residuales para SARS-CoV-2}

Hart y Halden, describen un modelo computacional que permite aclarar el panorama en cuanto al uso de la epidemiología, basada en el monitoreo de aguas residuales para SARS-CoV-2. El modelo está basado en la ciudad de Tempe, Arizona, Estados Unidos, con una población de 185038 habitantes y un área de 104 kilómetros cuadrados. La elaboración del modelo toma en cuenta diversos datos publicados en múltiples estudios, para obtener el cálculo de las variables a determinar (cantidad de excreción viral, por ejemplo). A partir de este modelo, los primeros resultados obtenidos fueron (13):

1) La carga viral de SARS-CoV-2 excretada en aguas residuales varía entre 56.6 millones a 11.3 billones de genomas virales por persona infectada al día.

2) Concentración de 0.15 a 141.5 millones de genomas virales por litro de agua residual.

Para obtener los resultados anteriores, se considera la excreción fecal de 600000 (reportada por Zhang et al) a 30000000 (reportada por Wolfel et al) genomas virales de SARS-CoV-2, por cada $2 \mathrm{ml}$ de materia fecal; se asume la excreta fecal entre 100-400 gramos de heces al día por persona con una densidad fecal de 1.06 gramos/ mililitro (13).

Adicionalmente, con base en este modelo, es posible predecir cuántos individuos con la enfermedad se requieren para detectar el genoma viral de SARS-CoV-2, en aguas residuales. El modelo reporta, que si se asume una detección mínima de 10 genomas ARN por mililitro de agua residual y no variabilidad en las variables, como flujo y temperatura del agua y generación de 50-500 litros de agua residual por persona al día, es necesario entre $0.88 \%$ ( 1 individuo con la enfermedad/114 personas sin la enfermedad) a 0.00005 $\%$ (1 individuo con la enfermedad/2 millones de personas sin la enfermedad) de personas con la enfermedad en la población para detectar ARN de SARS-CoV-2 en aguas residuales (13). 
González et al, realizaron un estudio en el sureste de Virginia, Estados Unidos, en donde se monitoreó por 21 semanas, un área de 3,100 millas cuadradas, con 18 ciudades y condados que albergan a 1.7 millones de personas. En dicho estudio, se monitorearon 9 PTAR principales y 7 PTAR alternas. El primer caso registrado fue el 9 de marzo de 2020 y para el 28 de julio de 2020, ya se contaba con 89994 casos registrados. La metodología del estudio se basó en recolectar un litro de muestras provenientes de afluentes de las PTAR, las cuales fueron procesadas con el método de reacción en cadena de polimerasa con transcriptasa reversa, abreviado RT-PCR por sus siglas en inglés, para detectar ARN de SARS-CoV-2 (7).
Dichos autores describen

detecciones esporádicas de genoma viral durante las primeras semanas de monitoreo, sin embargo, determinan un incremento de la carga de genoma viral a través del tiempo, lo cual se correlaciona con el incremento del número de casos y las fases de reapertura. Con los datos cuantitativos que se obtuvieron de las diversas PTAR a través del tiempo, se realizó un mapa de calor, en donde se identificó cada área según la carga de genoma viral, que se detectó en la PTAR, el cual recolecta el agua residual correspondiente a esa área en específico. La identificación de cada área se realizó con colores, en donde el color celeste representa las áreas con menor carga de genoma viral, las áreas amarillas representan áreas con carga moderada y las anaranjadas y rojas representan las áreas con mayor carga. Al comparar los mapas de calor desde el inicio del monitoreo, con los últimos mapas realizados al final del monitoreo, se observa que la mayoría de las áreas son señalizadas con color celeste al inicio y posteriormente pasan a color amarillo, y en algunos casos color anaranjado y rojo, reflejan, por tanto, el incremento de la carga de genoma viral a través del tiempo (7).

Implicaciones en el marco de salud pública: ¿Cómo podría contribuir esta herramienta epidemiológica en la actualidad y en la era post pandemia? 
Todas las potenciales utilidades, que se mencionaron anteriormente, pueden contribuir de manera significativa en el control de la pandemia; aunque ya se empezaron a comprobar algunas de estas utilidades, aún hacen falta más estudios que evalúen la viabilidad de esta herramienta epidemiológica en la pandemia de SARSCoV-2 $(2,7,8,12)$. Es importante considerar que, conforme decline la pandemia de SARS-CoV-2, es probable que se observe un incremento de brotes localizados en el nivel comunitario. En estos casos, podría ser utilizada como una herramienta pre-tamizaje para identificar áreas geográficas como hotspots y así priorizar las pruebas individuales en comunidades con recursos limitados $(7,13)$.

\title{
Retos de la epidemiología basada en el monitoreo de aguas residuales durante la pandemia de SARS-CoV-2
}

\begin{abstract}
Aunque la investigación del uso de esta herramienta en la pandemia de SARS-CoV-2 crece más conforme el tiempo transcurre y, cada vez se tienen más datos, aún hay retos que superar para que se pueda establecer como una herramienta clave durante la actual pandemia. A continuación, se enumeran los retos que la epidemiología basada en el monitoreo de aguas residuales debe afrontar $(8,12)$ :
\end{abstract}

1) Determinar con qué efectividad se puede correlacionar, la prevalencia de casos activos con la carga de genoma viral detectado en aguas residuales, si se toma en cuenta la variabilidad en la cantidad de excreción fecal de ARN, su duración y la persistencia diferenciada del genoma en aguas residuales. La diversidad de los datos podría provocar que los resultados no reflejen solamente casos activos, sino que también, casos clínicamente resueltos.

2) Comprender la variabilidad cuantitativa y la duración de la excreción del ARN viral.

3) Determinar un método estándar de muestreo y concentración de la muestra, así como el enfoque ideal para detección del genoma viral (cualitativa, semicuantitativa, cuantitativa).

4) Determinar la población que sea representada por cada PTAR, así como tomar en cuenta que, depende de en qué PTAR se obtengan la muestra y que flujos de aguas residuales reciba; algunas áreas que no formen parte de ese sistema o que tengan su propia PTAR, no serán captados.

5) No crear pánico y ansiedad en la población al comunicar los resultados obtenidos. Se debe hacer conciencia que, aunque aún no se tiene una respuesta definitiva, los resultados positivos representan «residuos virales» y no virus viable («virus vivo») con potencial infeccioso. 


\section{Referencias}

1. Wiersinga W, Rhodes A, Cheng A, Peacock S, Prescott H. Pathophysiology, Transmission, Diagnosis, and Treatment of Coronavirus Disease 2019 (COVID-19). JAMA. 2020;324(8):782-793. https://jamanetwork.com/journals/jama/ fullarticle/2768391

2. Kitajima M, Ahmed W, Bibby K, Carducci A, Gerba C, Hamilton K et al. SARS-CoV-2 in wastewater: State of the knowledge and research needs. Science of The Total Environment. 2020;739:782-793. https://doi.org/10.1016/j. scitotenv.2020.139076

3. Mandal P, Gupta A, Dubey B. A review on presence, survival, disinfection/removal methods of coronavirus in wastewater and progress of wastewater-based epidemiology. Journal of Environmental Chemical Engineering. 2020;8(5):104317. https://doi.org/10.1016/j.jece.2020.104317

4. Langone M, Petta L, Cellamare C, Ferraris M, Guzzinati R, Mattioli D et al. SARS-CoV-2 in water services: Presence and impacts. Environmental Pollution. 2021;268:115806. https://doi.org/10.1016/j.envpol.2020.115806

5. World Health Organization. Transmission of SARS-CoV-2: implications for infection prevention precautions. 2020. Disponible en: https://www.who.int/news-room/commentaries/detail/transmission-of-sars-cov-2-implications-forinfection-prevention-precautions

6. Amirian E. Potential fecal transmission of SARS-CoV-2: Current evidence and implications for public health. International Journal of Infectious Diseases. 2020;95:363-370. https://doi.org/10.1016/j.ijid.2020.04.057

7. Gonzalez R, Curtis K, Bivins A, Bibby K, Weir M, Yetka K et al. COVID-19 surveillance in Southeastern Virginia using wastewater-based epidemiology. Water Research. 2020;186:116296. https://doi.org/10.1016/j.watres.2020.116296

8. Daughton C. Wastewater surveillance for population-wide Covid-19: The present and future. Science of The Total Environment. 2020;736:139631. https://doi.org/10.1016/j.scitotenv.2020.139631

9. Arslan M, Xu B, Gamal El-Din M. Transmission of SARS-CoV-2 via fecal-oral and aerosols-borne routes: Environmental dynamics and implications for wastewater management in underprivileged societies. Science of The Total Environment. 2020;743:140709. https://doi.org/10.1016/j.scitotenv.2020.140709

10. Ahmed W, Bertsch P, Angel N, Bibby K, Bivins A, Dierens L et al. Detection of SARS-CoV-2 RNA in commercial passenger aircraft and cruise ship wastewater: a surveillance tool for assessing the presence of COVID-19 infected travellers. Journal of Travel Medicine. 2020;27(5). https://doi.org/10.1093/jtm/taaa116

11. Cheung K, Hung I, Chan P, Lung K, Tso E, Liu R et al. Gastrointestinal Manifestations of SARS-CoV-2 Infection and Virus Load in Fecal Samples From a Hong Kong Cohort: Systematic Review and Meta-analysis. Gastroenterology. 2020;159(1):81-95. https://doi.org/10.1053/j.gastro.2020.03.065

12. Martin J, Klapsa D, Wilton T, Zambon M, Bentley E, Bujaki E et al. Tracking SARS-CoV-2 in Sewage: Evidence of Changes in Virus Variant Predominance during COVID-19 Pandemic. Viruses. 2020;12(10):1144. https://doi.org/10.3390/ v12101144

13. Hart O, Halden R. Computational analysis of SARS-CoV-2/COVID-19 surveillance by wastewater-based epidemiology locally and globally: Feasibility, economy, opportunities and challenges. Science of The Total Environment. 2020;730. https://doi.org/10.1016/j.scitotenv.2020.138875 